\title{
Server Virtualization Technology: A proposed Implementation Model
}

\author{
Felix M. Obegi ${ }^{1 *} \quad$ George Raburu ${ }^{2} \quad$ Michael O. Okoya $^{3}$ \\ 1.Faculty of Commerce, Management Science, Egerton University \\ 2.School of Informatics and Innovative Systems, Jararamogi Oginga Odinga, University of Science and \\ Technology \\ 3.School of Mathematics and Actuarial Sciences, Jaramogi Oginga Odinga University of Science and \\ Technology
}

\begin{abstract}
The study sought to fill the existing gap on issues surrounding the implementation of Server virtualization technology, which have received relatively little attention.. The study investigated the implementation of server virtualization technology by companies listed in the Nairobi Securities Exchange. It employed a correlational research design and targeted the IT and Operations departments of listed companies on the NSE. The target population consisted of 120 persons, and the study used a census method. Primary data was collected through use of questionnaires. Data collected was sorted, coded and input into the statistical package for social sciences (SPSS) version 21.0 for production of graphs, tables, descriptive statistics and inferential statistics. Correlation analysis revealed that environmental factors, technological factors, organizational factors and human factors had a positive and significant association with server virtualization implementation.
\end{abstract}

DOI: $10.7176 / \mathrm{IKM} / 9-4-01$

Publication date: April $30^{\text {th }} 2019$

\subsection{Introduction}

Organizations today have diversified their operations. Many organizations have various branches with one headquarter. These geographical distributions of workforce create challenges in management of data (Metzler, 2011). Management of emails, sharing of files, critical applications of missions, and evaluation and monitoring of employees productivity are some of the issues that require advanced data management (Kirinya, 2014). Initially, organizations computed resources and spread them to the various branches. With time, this proved to be a waste of resources, financially, physically and in terms of human resource (Bagchi, 2012).

According to Li and Yang (2010), virtual server technology issue has become one of the greatest concerns to the IT field in the $21^{\text {st }}$ century. The features of virtual server technology may include super-large scale, dynamic scalability, and on-demand deployment in which virtualization plays a central role and the industry realizes its importance and begins to implement it. Virtualization has such advantage as having a single server to carry multiple operating systems. It not only saves the quantity of purchased servers, reduces the management and the maintenance costs, but also reduces the consumption of electricity and cooling power. The global market of virtualization technology is now on the rise. According to the forecast by Global Industry Analysts, Inc., the global virtualization software market is projected to reach US $\$ 11.98$ billion by 2015 (Global Industry Analysts, Inc. [GIA], 2010).

According to Healey, Anderson \& Humphreys (2008), server virtualization is a consolidating technology, which is being used to optimize server resources and to enhance productivity. Server virtualization, also referred to as system-level virtualization, has several, although similar, definitions, all evolving around the concept of abstracting the physical computer hardware interaction of operating system software, and enabling several instances of operating systems to execute simultaneously within the same physical system, or simplified as a virtual machine is taken to be an efficient, isolated duplicate of the real machine, or simply that a virtual machine, is now generally accepted as a software replica of a complete computer system.

Server virtualization offers numerous benefits to data centers everywhere in terms of power and cooling savings, space utilization, reduced application, backup and operating software licensing costs, and decreased man-hour costs. These benefits are achieved by increasing virtual machine density through a balance of CPU power and cost-effective memory footprints and when virtual these environments can be managed more efficiently, more securely, and with better Quality of Service (QoS) (Dubie, 2007).

The Nairobi Securities Exchange (NSE) is the principal stock exchange of Kenya. It began in 1954 to oversee stock exchange in Kenya. The NSE is Africa's fourth largest stock exchange in terms of trading volumes, and fifth in terms of market capitalization as a percentage of GDP. The Exchange works in cooperation with the Uganda Securities Exchange and the Dar es Salaam Stock Exchange, including the cross listing of various equities.

The implementation of server virtualization is crucial to the growth of the Nairobi Securities Exchange (NSE), which is the principal stock exchange of Kenya. It began in 1954, and it is currently Africa's fourth 
largest stock exchange in terms of trading volumes, and fifth in terms of market capitalization as a percentage of GDP. The NSE works in cooperation with the Uganda Securities Exchange and the Dar es Salaam Stock Exchange, including the cross listing of various equities (Kibuthu, 2005).

Companies listed in the various stock exchange(s) in the world tend to be industry leaders in various aspects of technology adoption. Therefore, the companies listed in the Nairobi Securities Exchange (NSE) would have an influence on the adoption and implementation of server virtualization in Kenya. Most of Kenya's Small and Medium sized companies look towards the big corporations listed on the NSE to see how they react to the new technology wave such as server virtualization, its adoption and implementation. Therefore, before implementing server virtualization technology, it is important to seriously plan and consider virtualization risks associated with it, the success factors, adoption and implementation models. It is also important for the organization to check whether it has the necessary infrastructure, capacity to handle the increased power and cooling densities, security issues emanating from server virtualization and the cost elements that arise due to the implementation of virtualization. It is also important to consider the failure of single consolidated server, because it is handling the workload of multiple applications. In order to properly implement server virtualization, there is a need to review literature on some of the issues mentioned above.

\subsection{Statement of the Problem}

Server virtualization technology has been regarded as a major contributor to business productivity, organizations' competitiveness, cost reduction and reduction in energy consumption (McGee, 2010). However, the implementation of server virtualization technology in Kenya has been slow with practical difficulties in getting the systems operational (Ernst \& Young, 2016). Furthermore, there is little discussion on implementation and management models of server virtualization technology or the consequences of these models for the companies and the customers. In fact, there appears to be little consideration of the factors that affect server virtualization implementation among companies listed in the Nairobi Securities Exchange.

Despite the acknowledgement of the importance of server virtualization, Bitta (2012) reckons that majority of organizations listed in the NSE have not fully implemented this technology. Due to lack of server virtualization implementation, majority of the companies listed in the NSE have not been operating efficiently. Majority of the organizations are not very productive and lack competiveness. Previous studies have been conducted on server virtualization implementation. For example, Uddin and Rahman (2011) studied virtualization implementation of a model for cost effectives and efficient data centers. The study found that server virtualization leads to cost reduction. Bose and Luo (2010) studied integrative framework for assessing firms' potential to undertake Green IT initiatives via virtualization. The study found that Green IT was vital in cost reduction. Bagchi, (2012); Metzler, (2011); Ogunyemi, (2009); Bitta, (2011) in their studies acknowledged the importance of server virtualization in cost reduction. Rahman (2011) identified organizational factors such as leadership support and competence as determinants of successful server implementation.

\subsection{Research Objective}

To propose and validate a suitable success model for server virtualization implementation technology

\subsection{Literature review}

Virtualization emerged as an alternative technology in the IT industry around 1960. The concept of virtualization was introduced by IBM and they divided to UNIX mainframe to multiple logic units. Popek and Goldberg (1974) defined a virtual machine as an improved version of traditional machines. There were specifications that dictated the development of a virtual machine. These included the presence statistical dominant instruction from VMM to increase efficiency, full control of all IT infrastructure and behavioural tendencies similar to those of traditional machines.

Server or machine virtualization is the most common method of virtualization (von Hagen 2008). In server virtualization, the whole machine runs independently in a virtual system. It has a separate operating system as well as hardware and networking capabilities. The virtual server is displayed to users as a separate physical server although there can be several similar systems in one physical environment. Virtualization abstracts the underlying physical structure of various technologies. Virtualization, in computing, is the creation of a virtual (rather than actual) version of something, such as a hardware platform, operating system, a storage device or network resources. Server virtualization creates multiple isolated environments, allows multiple OS's and workloads to run on the same physical hardware, and solves the problem of tight coupling between OS's and hardware. In a context of using it through an organization, it refers as platform virtualization: a technology that allows several different systems to run on a single physical server, possibly through a network (Baschab, Piot \& Carr 2007; Golden 2007).

Virtualization, in computing, is the creation of a virtual (rather than actual) version of a hardware platform, operating system, storage device or network resources (von Hagen 2008). Server virtualization creates numerous 
isolated environments, and allows multiple Operating Systems's and workloads, to run on the same CPU/server. A virtual machine (VM) is an abstraction layer or environment between hardware components and the end-user. Virtual machines run operating systems and application software and can run many virtual machines while sharing system hardware components such as CPUs, controllers, disk, memory, and I/O among virtual servers (Kreuter, 2004).

A "real machine" is the host operating system and hardware components, sometimes described as "bare metal," such as memory, CPU, motherboard, and network interface. The real machine is essentially a host system with no virtual machines. The real machine operating system accesses hardware components by making calls through a low-level program called the BIOS (basic input/output system). Virtual machines are built on top of the real machine core components. Goldberg describes virtual machines as "facsimiles" or a "hardwaresoftware duplicate of a real existing machine" (Goldberg 1971a, 1971b, cited in Daniels, 2009).

\subsection{Theoretical Framework}

This study adopted the resource-based theory that has been articulated by a number of authors. The resourcebased theory is part of the theories that consider the resources as the foundations for a firm's strategy (Goles \& Chin, 2005). Barney (1991) defines firm resources as "all assets, capabilities, organizational processes, firm attributes, information, knowledge, etc". Resources are enablers of conceiving strategy and implementation in a way to improve the firm efficiency and effectiveness. In his extensive study about resource-based theory, Barney (1991) categorizes resources in three different groups: physical capital resources, human capital resources and organizational capital resources. But how these are adopted, gives a firm a competitive advantage.

\subsection{Technology Adoption Models}

Based on the existing literature, the study reviewed three technological models; namely TechnologyOrganization-Environment (TOE), Technology acceptance Model (TOEM) and Diffusion of Innovation.

The research model proposed is an integration of TOE, TAM and DOI. The research model will also add one new construct "human factor" to be integrated with TAM, DOI \& TOE constructs. The new model is called TOEH which will look at the effects of Technology, organizational characteristics, environmental and human factors on the adoption of server virtualization technology by companies listed on the Nairobi Securities Exchange .The research adopted only the factors considered more important as per the literature review and case studies.

\subsubsection{Technology-Organization-Environment (TOE)}

The TOE framework was introduced by Tornatzky and Fleischer (1990), and it uses three elements that influence technological adoption; the environmental context, the organization context, and the technological context. Technological refers to both internal and external technologies used in an organization. Organizational refers to the characteristics of the organization while the Environmental refers to the environment surrounding the organization including the working partners, competitors and the government regulations. According to DePetro et al. (1990), internal and external factors affect successful implementation of innovative technologies. These factors include availability of resources, expertise, leadership, market competition, government policies and regulatory environment and unforeseen eventualities. These factors may act as a propellant or deterrent to ICT adoption.

Though TOE theory has been criticized for lack of a concrete model describing how these factors influence adoption decisions (Zhu and Kraemer, 2005), many studies relied on this theory to advance their arguments on server virtualization adoption.

\subsubsection{Technology acceptance Model (TAM)}

Davis' (1989) TAM is widely used to study user acceptance of technology. The original TAM model predicts acceptance based on the end-user's perceived usefulness (PU) and perceived ease of use (PEOU) of the technology for a specific purpose. Davis applied the model to work settings, and defined PU as "the degree to which a person believes that using a particular system would enhance his or her job performance".

TAM suggests the acceptance of technology is influenced by perceived ease of use, perceived usefulness and subjective norm or perceived satisfaction.TAM model which deals with perceptions as opposed to real usage, suggests that when users are presented with a new technology, two important factors influence their decision about how and when they will use it (Davis, 1989). According to TAM, perceived usefulness (PU) and perceived ease of use (PEOU) influence one's attitude towards system usage, which influences one's behavioural intention to use a system, which, in turn, determines actual system usage.

\subsubsection{Diffusion of Innovation (DOI)}

Diffusion of Innovation (DOI) theory is another popular model used in information systems research to explain user adoption of new technologies. Rogers defines diffusion as 'the process by which an innovation is communicated through certain channels over time among the members of a social society' (Rogers, 1995). DOI theory sees innovations as being communicated through certain channels over time and within a particular social 
system. According to Nripendra, Yogesh, Michael (2013), the rate of diffusion is affected by an innovation's relative advantage, complexity, compatibility, trialability and observability but only three of its constructs (i.e. compatibility, complexity, and relative advantage) were in use across various studies: 1)Relative Advantage The degree to which an innovation is seen as better than the idea, program, or product it replaces.2) Compatibility - How consistent the innovation is with the values, experiences, and needs of the potential adopters.3)Complexity - How difficult the innovation is to understand and/or use.4) Triability - The extent to which the innovation can be tested or experimented with before a commitment to adopt is made and 5) Observability - The extent to which the innovation provides tangible results

The research adopted only the factors considered more important as per the literature review and case studies. The study left out the factors which were repeated in some models so as to avoid repetition s shown in table 2.1 below.

Table 2.1: Factors and Variables for the Models

\begin{tabular}{|c|c|c|c|c|}
\hline Models & Constructs & Used in developing ТОЕН & Not used & $\begin{array}{l}\text { Added factors from } \\
\text { Literature Review }\end{array}$ \\
\hline DOI & $\begin{array}{l}\text { Human factors } \\
\text { Adequacy of manpower } \\
\text { Skilled personnel } \\
\text { Training }\end{array}$ & $\begin{array}{l}\text { Human factors } \\
\text { Adequacy of manpower } \\
\text { Skilled personnel } \\
\text { Training }\end{array}$ & & \\
\hline TAM & $\begin{array}{l}\text { Perceived Usefulness } \\
\text { Perceived Ease of Use }\end{array}$ & $\begin{array}{l}\text { Perceived Usefulness } \\
\text { Perceived Ease of Use }\end{array}$ & & \\
\hline TOE & $\begin{array}{l}\text { Organizational factors } \\
\text { Formal and informal } \\
\text { linking structures } \\
\text { Communication } \\
\text { processes } \\
\text { Size } \\
\text { Slack } \\
\text { Technological } \\
\text { Availability } \\
\text { Characteristics } \\
\text { Environmental factors } \\
\text {-Industry characteristics } \\
\text { and market structure } \\
\text {-Technology support } \\
\text { infrastructure } \\
\text {-Government regulation }\end{array}$ & $\begin{array}{l}\text {-Organizational factors } \\
\text {-Organization culture } \\
\text {-Organization size } \\
\text { Organization Resources } \\
\text { Technological } \\
\text {-Compatibility } \\
\text {-Security } \\
\text {-Privacy } \\
\text { Environmental factors } \\
\text {-Industry competition } \\
\text {-Regulatory Environment } \\
\text {-Developing Environment }\end{array}$ & $\begin{array}{l}\text {-Formal and } \\
\text { informal linking } \\
\text { structures } \\
\text {-Communication } \\
\text { processes }\end{array}$ & -Complexity \\
\hline
\end{tabular}

\subsection{Research methodology}

The study adopted a correlational survey research design. The study aimed at determining the critical factors influencing successful implementation of sever virtualization technology of companies listed on the NSE. The population of interest in this study comprised of companies listed at the Nairobi Securities Exchange. There were 60 companies listed at the Nairobi Securities Exchange as of May 2013 (NSE, 2013). The target population was the management employees working in the IT department and operations department.

Table 3.1 Summary of Objectives, data collection techniques, analysis and interpretation

\begin{tabular}{|l|l|l|}
\hline Objectives & Data Collection Method & Analysis Technique \\
\hline $\begin{array}{l}\text { To propose and validate a suitable success } \\
\text { model for server virtualization } \\
\text { implementation technology }\end{array}$ & $\begin{array}{l}\text { Questionnaires } \\
\text { Derive from existing frameworks }\end{array}$ & $\begin{array}{l}\text { Expert evaluation and reviews } \\
\text { Structural Equation Modeling }\end{array}$ \\
\hline
\end{tabular}

\subsection{Model modification and Testing}

The first stage was analysis of the model which was by running regression and correlations among the various variables. This was done to help in formulating the model, coming up with the correct questionnaire and then data collection. The second stage was to identify relationship between the variables.

According to Lule et al, (2012), to modify the model and see which variables are the best at explaining the variance in adoption, factors analysis and structural equation modeling is used. Specifically, SPSS 21 and AMOS module was used to perform Structural Equation Modeling (SEM). This is Structural Equation Modeling 
(SEM) software that uses Confirmatory Factor Analysis (CFA) to align the tested measures to the specific constructs and constraining the variances of each measure to the latent construct it should represent. In addition to assessing the degree to which each measure contributes to its latent construct, CFA also tests the separation between constructs by evaluating the fit in the overall model.

\subsection{Results and Discussions}

\subsection{Response Rate}

The data was collected from all the listed firms in the Nairobi Securities Exchange (NSE). Out of the 120 questionnaires administered, 103 questionnaires were properly filled and returned. This gave a respondent rate of $86 \%$ as shown in Table 4.1. This percentage is rated as very good. A response rate of $50 \%$ is adequate, $60 \%$ is good and 70\% and above is very good (Mugenda \& Mugenda, 2003). Therefore, $86 \%$ response rate in this study was adequate for analysis and according to Babbie (2004), a return rate of 50\% is acceptable to analyze and publish, $60 \%$ is good and above $70 \%$ is rated very good. The high response rate was as a result of the researcher contacting the respondents through email and telephone calls before the exercise of data collection and requesting them to complete the questionnaires.

\section{Table 4.1: Response Rate}

\begin{tabular}{lll}
\hline Response & Frequency & Percent \\
\hline Returned & 103 & $86 \%$ \\
Not-returned & 17 & $14 \%$ \\
Total & $\mathbf{1 2 0}$ & $\mathbf{1 0 0}$ \\
\hline
\end{tabular}

Source: Author, (2017)

\subsection{Overall Correlation Analysis}

Results in table 4.2 indicate the correlation analysis between success factors and server virtualization technology implementation (SVIT). The correlation results revealed that there was a positive and a significant association between environmental factors $(E F)$ and server virtualization technology implementation $(r=0.668, p=0.000)$. Further, results indicated that there is a positive and a significant association between technological factors (TF) and server virtualization technology implementation $(\mathrm{r}=0.809, \mathrm{p}=0.000)$. In addition, results revealed that there is a positive and a significant association between organizational factors (OF) and server virtualization technology implementation $(\mathrm{r}=0.718, \mathrm{p}=0.000)$. Lastly, results showed that there is a positive and a significant association between human factors (HF) and server virtualization technology implementation $(\mathrm{r}=0.698, \mathrm{p}=0.000)$. This implied that when success factors change, server virtualization technology implementation also changes.

Table 4.2: Overall Correlation Analysis

\begin{tabular}{|c|c|c|c|c|c|c|}
\hline & & SVTI & EF & TF & OF & HF \\
\hline SVTI & $\begin{array}{l}\text { Pearson Correlation } \\
\text { Sig. (2-tailed) }\end{array}$ & 1.000 & & & & \\
\hline EF & $\begin{array}{l}\text { Pearson Correlation } \\
\text { Sig. (2-tailed) }\end{array}$ & $\begin{array}{l}.668 * * \\
0.000\end{array}$ & 1.000 & & & \\
\hline TF & $\begin{array}{l}\text { Pearson Correlation } \\
\text { Sig. (2-tailed) }\end{array}$ & $\begin{array}{c}.809 * * \\
0.000\end{array}$ & $\begin{array}{l}.718 * * \\
0.000\end{array}$ & 1.000 & & \\
\hline OF & $\begin{array}{l}\text { Pearson Correlation } \\
\text { Sig. (2-tailed) }\end{array}$ & $\begin{array}{l}.718^{* *} \\
0.000\end{array}$ & $\begin{array}{l}.541 * * \\
0.000\end{array}$ & $\begin{array}{l}.651^{* *} \\
0.000\end{array}$ & 1.000 & \\
\hline HF & $\begin{array}{l}\text { Pearson Correlation } \\
\text { Sig. (2-tailed) }\end{array}$ & $\begin{array}{c}.698 * * \\
0.000\end{array}$ & $\begin{array}{c}.664 * * \\
0.000\end{array}$ & $\begin{array}{c}.697 * * \\
0.000\end{array}$ & $\begin{array}{l}.807 * * \\
0.000\end{array}$ & 1.000 \\
\hline
\end{tabular}

\subsection{Multiple Regression Analysis}

The results presented in table 4.3 present the fitness of model used of the regression model in explaining the study phenomena. Environmental factors, technological factors, organizational factors and human factors were found to be satisfactory variables in explaining server virtualization implementation. This is supported by coefficient of determination also known as the $\mathrm{R}$ square of $72.6 \%$. This means that environmental factors, technological factors, organizational factors and human factors explain $72.6 \%$ of the total variations in the dependent variable which is server virtualization implementation by companies listed on the Nairobi Securities Exchange. The results further mean that the model applied to link the relationship of the variables was satisfactory. 
Table 4.3: Model Fitness

\begin{tabular}{lc}
\hline Variables & Coefficients \\
\hline $\mathrm{R}$ & 0.852 \\
R Square & 0.726 \\
Adjusted R Square & 0.715 \\
Std. Error of the Estimate & 0.10707 \\
\hline
\end{tabular}

In statistics significance testing the $p$-value indicates the level of relation of the independent variable to the dependent variable. If the significance number found is less than the critical value also known as the probability value (p) which is statistically set at 0.05 , then the conclusion would be that the model is significant in explaining the relationship; else the model would be regarded as non-significant.

Table 4.4 provides the results on the analysis of the variance (ANOVA). The results indicate that the overall model was statistically significant. Further, the results imply that the independent variables are good predictors of server virtualization implementation. This was supported by an F statistic of 64.826 and the reported $p$ value (0.000) which was less than the conventional probability of 0.05 significance level.

Table 4.4: Analysis of Variance

\begin{tabular}{lrrrrr}
\hline & Sum of Squares & df & Mean Square & F & Sig. \\
\hline Regression & 2.973 & 4 & .743 & 64.826 & $.000^{\mathrm{b}}$ \\
Residual & 1.123 & 98 & .011 & & \\
Total & 4.096 & 102 & & & \\
\hline
\end{tabular}

Source: Author, (2017).

Table 4.5: Regression of coefficient

\begin{tabular}{lcccc}
\hline & B & Std. Error & t & Sig \\
\hline (Constant) & .801 & .213 & 3.764 & .000 \\
Environmental Factors & .119 & .056 & 2.134 & .012 \\
Technological Factors & .368 & .062 & 5.893 & .000 \\
Organizational Factors & .245 & .073 & 3.370 & .001 \\
Human Factors & .121 & .055 & 2.220 & .000 \\
\hline
\end{tabular}

Source: Author, (2017)

Thus, the optimal model for the study is;

Server Virtualization Implementation $=0.801+0.119 \mathrm{X}_{1}+0.368 \mathrm{X}_{2}+0.245 \mathrm{X}_{3}+0.121 \mathrm{X}_{4}$ Where,

$\mathrm{X}_{1}=$ Environmental Factors

$\mathrm{X}_{2=}$ Technological Factors

$\mathrm{X}_{3}=$ Organizational Factors

$\mathrm{X}_{4}=$ Human Factors

\subsection{Proposed Model}

Based on the results in figure 4.1 a model optimization was conducted. The aim of model optimization was to guide in derivation of the final model (revised conceptual framework) where only the significant variables are included for objectivity. Results in Table 4.1 were arrived at through running multiple regressions. No variable was dropped since all the variables were significant. The variables were arranged in order of significant as follows; technological factors, organizational factors, human factors and environmental factors. Therefore, the revised model shows that technological factors best explains implementation of server virtualization technology, followed by organizational factors, then human factors and lastly environmental factors.

The figure 4.1 shows the structural equation modeling results that were used to derive the proposed model. 


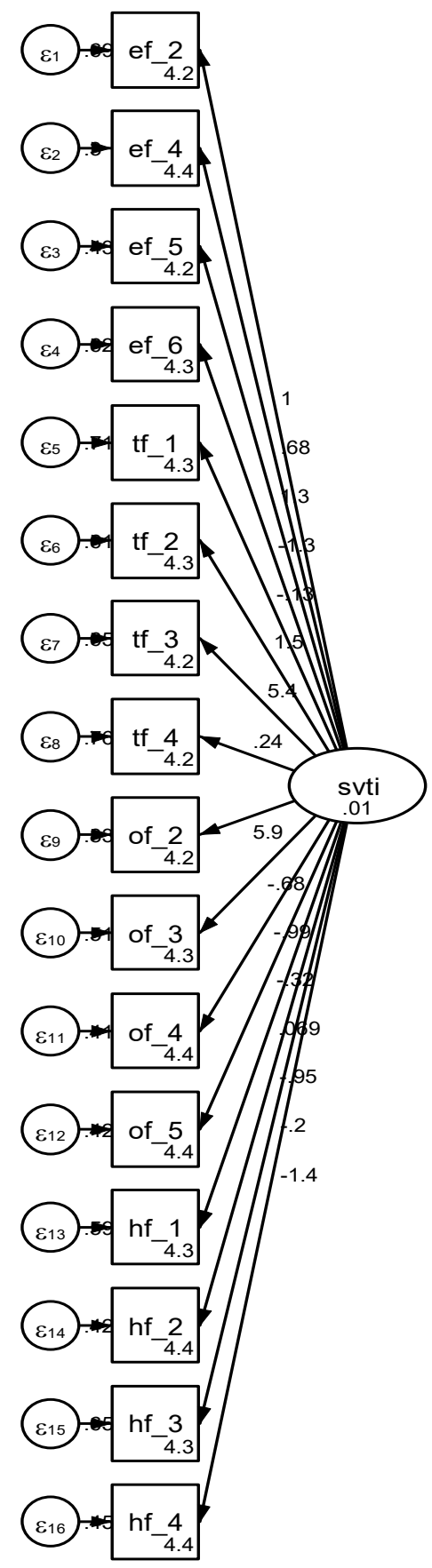

Figure 4.1: Structural Equation Model (SEM)

The proposed model from structural Equation modeling proposed that technological factors best explains sever virtualization technology implementation, followed by organizational factors, then human factors and lastly environmental factors. To validate the proposed model, expert analysis was used. Validation results are shown in the next section.

\subsection{Validation of the proposed Model}

Table 4.6 shows validation of the proposed model results. The researcher interviewed 10 experts in the field of technology implementation. The experts were required to the rate the influence of the following factors on server virtualization implementation using a scale of 1 to 5 . On environmental factors, majority of the experts rated Energy (power) requirements (mean=4.4) as being more important, followed by conservation requirements (4.1), then economic growth (3.4) and lastly political system (3.1). On technological factors, majority of the experts rated Information Protection-Privacy (4.8) as being more important, followed by cost reduction (4.7), then 
security standards (4.6) and lastly technological capability (4.4).

On organization factors; majority of the experts rated organization resources (4.4) as being more important, followed by organization staff support (4.2), then organization culture (4.0) and lastly organization size (3.6). On human factors, majority of the experts rated skilled personnel (4.4) as being important, followed by data management skills (4.1), then staff training (4.0) and lastly adequacy of manpower (3.9).

Experts added some of the factors they felt were important in virtual server implementation, namely; compatibility with existing technology, Cost of maintenance, ICT governance and Quality of service.

The proposed model was therefore validated implying that environmental factors, technical factors, organizational factors and human factors influence server virtualization implementation.

Table 4.6: Model Validation Results

\begin{tabular}{llrr}
\hline & Factors & Observations & Mean \\
\hline Environmental Factors & Political system with organization & 10 & 3.1 \\
& Energy (power) requirements & 10 & 4.4 \\
& Conservation requirements & 10 & 4.1 \\
& Economic growth & 10 & 3.4 \\
\hline Technological Factors & Cost Reduction & 10 & 4.7 \\
& Technology Compatibility & 10 & 4.4 \\
& Information Protection-Privacy & 10 & 4.8 \\
& Security standards & 10 & 4.6 \\
\hline Organizational Factors & Organization culture & 10 & 4.0 \\
& Organization size & 10 & 3.6 \\
& Organization Resources & 10 & 4.4 \\
& Organization staff support & 10 & 4.2 \\
\hline Human Factors & Adequacy of manpower & 10 & 3.9 \\
& Skilled personnel & 10 & 4.4 \\
& Staff Training & 10 & 4.0 \\
& Data management skills & 10 & 4.1 \\
\hline
\end{tabular}

Source: Author, (2017)

\section{REFERENCES}

Bagchi, S. (2012). Define security policies when considering virtualization. Retrieved $4^{\text {th }}$ August, 2014, from http://www.cxotoday.com/story/define-security-policies-when-considering-virtualization/

Baschab, J., Piot, J., \& Carr, N. (2007). The Executive's guide to information technology. Boston: John Wiley \& Sons.

Bitta, M.N. (2012). A framework to guide companies on adapting cloud computing technology. Unpublished thesis. Computer based information systems. Strathmore university

Bose, L.\& Luo, X. (2011). Integrative framework for assessing firms' potential to undertake Green IT initiatives via virtualization - A theoretical perspective, Journal of Strategic Information Systems 20: 38-54

Dubie, D. (2007). Managing virtualized servers is no easy task. Network World, 24(43), 1, 43-46.

Ernst \& Young (2011). Cloud computing issue and impact. Retrieved $2^{\text {nd }}$ July, 2014, from http://www.ey.com/Publication/vwLUAssets/Cloud_computing_issues_impacts_and_insights/\$File/Cloud $\% 20$ computing\%20issues\%20and20impacts 14Apr11.pdf

Goles, T., \& Chin, W.W. (2005). Information systems outsourcing relationship factors: Detailed conceptualization and initial evidence. The Data Base for Advances in Information Systems, 36 (4), 47-57.

Healey, M. T., Anderson, C. \& Humphreys, J. (2008). The value propositions of server virtualisation and services. Chicago: IDC.

Kibuthu W. (2005). Capital Markets in Emerging Economies, A Case Study of the Nairobi Stock ExchangeUnpublished MA dissertation, Tufts University

Kiriinya, D. (2014). Factors Influencing Cloud Computing Adoption in Organisations: A Case of Cooperative Insurance Company of Kenya (Doctoral dissertation, United States International University-Africa). Knowledge Management, Vol 6, No.3:2224-5758

Li, Q., \& Yang, C. (2010). Development trends of MIS based on cloud computing environment. In $3^{\text {rd }}$ International Symposium of Information Science Engineering, 145-148.

McGee, K. (2010). The 2010 Gartner scenario: The current state and future of the IT industry., Stamford CT: Gartner.

Metzler, J. (2011). Virtualization: Benefits, challenges, and solutions. San Francisco, CA: Riverbed Technology, Inc.

Ogunyemi, A. (2009). Towards an organizational readiness framework for emerging technologies: an investigation of antecedents for South African organizations' readiness for server virtualization. Retrieved 
July 2, 2013, from http://academia.edu/1854906/T

Ogunyemi, A. A., \& Johnston, K. A. (2012). Exploring the roles of people, governance and technology in organizational readiness for emerging technologies. The African journal of information systems, 4(3), 2.

Popek and Goldberg (1974):Virtualization Requirements

Rahman M.A.A. (2010). Server consolidation: An Approach to make data centers energy efficient \& green. International Journal of Scientific and Engineering Research, 1, (1).

Uddin, M. \& Rahman, A.A. (2011). Virtualization implementation model for cost effective and efficient data centers. International Journal of Advanced Computer Science and Applications, 2 (1).

Uddin, M., Talha, M., Rahman, A, Shah, A. \& Ahmed, J. (2012). Green information

Von Hagen, W. (2008). Professional XEN virtualization. Indianapolis, Indiana: Wiley Publishing Inc. 